\title{
P Wave Indices-Advancing Our Understanding of Atrial Fibrillation-Related Cardiovascular Outcomes
}

\author{
Lin Y. Chen ${ }^{1 *}$ and Elsayed Z. Soliman ${ }^{2}$ \\ ${ }^{1}$ Cardiovascular Division, Department of Medicine, University of Minnesota Medical School, Minneapolis, MN, United States, \\ ${ }^{2}$ Department of Epidemiology and Prevention, Wake Forest University Health Sciences, Winston-Salem, NC, United States
}

OPEN ACCESS

Edited by:

Georges Nemer,

American University of Beirut,

Lebanon

Reviewed by:

Alexander Maass,

University Medical Center Groningen,

Netherlands

Jose Francisco Huizar

Hunter Holmes McGuire VA Medical

Center, United States

*Correspondence:

Lin Y. Chen

chenx484@umn.edu

Specialty section:

This article was submitted to Cardiovascular Genetics and Systems

Medicine,

a section of the journal

Frontiers in Cardiovascular Medicine

Received: 18 January 2019

Accepted: 16 April 2019

Published: 03 May 2019

Citation:

Chen LY and Soliman EZ (2019)

$P$ Wave Indices - Advancing Our

Understanding of Atrial

Fibrillation-Related Cardiovascular

Outcomes.

Front. Cardiovasc. Med. 6:53.

doi: 10.3389/fcvm.2019.00053
Atrial fibrillation (AF) is associated with an increased risk of ischemic stroke, heart failure, cognitive decline, dementia, myocardial infarction, sudden cardiac death (SCD), and all-cause death. Although these associations are firmly established, our understanding of the underlying mechanisms remains incomplete. Accumulating evidence suggests that left atrial $(\llcorner A)$ abnormality or atrial cardiomyopathy may explain the relationship of $A F$ to the aforementioned outcomes. P-wave indices (PWIs) reflect underlying atrial remodeling. In this mini review, we define representative PWIs, discuss state-of-the-art knowledge on the relationship between abnormal PWIs and AF-related cardiovascular outcomes (focusing on ischemic stroke and sudden cardiac death), and propose directions for future research. Our ultimate goal is to present a practical way forward to advance the emerging field of LA abnormality or atrial cardiomyopathy.

Keywords: atrial fibirillation, stroke, $\mathrm{P}$ wave indices, $\mathrm{P}$ wave duration, $\mathrm{P}$ wave axis

Atrial fibrillation (AF) is the most common sustained cardiac arrhythmia, and its prevalence is increasing over time $(1,2)$. AF is associated with an increased risk of ischemic stroke (3), heart failure (4), cognitive decline $(5,6)$, dementia (6), myocardial infarction (7), sudden cardiac death (SCD) $(8-10)$, and all-cause death $(8,11,12)$. Although these associations are firmly established, our understanding of the underlying mechanisms remains incomplete. The AF-stasis hypothesis is a widely accepted mechanism for AF-related thromboembolism (13); however, recent data compel us to re-evaluate this hypothesis: Novel insights into the lack of temporal relationship between AF episodes and ischemic stroke events in AF patients $(14,15)$, and data linking markers of left atrial (LA) abnormality or atrial cardiomyopathy with ischemic stroke in the absence of AF $(16,17)$, suggest that some entity - other than the irregular rhythm of AF-may be driving the risk of thromboembolism.

LA abnormality or atrial cardiomyopathy is an entity that encompasses alterations in macro- and micro-structure; reservoir, conduit, and contractile function; and electrical conduction in the atria (18). Molecular changes involving endothelial function, coagulation, inflammation, oxidative stress, and other pathways also fit into this paradigm (18). Methods to detect these alterations are diverse-such as magnetic resonance imaging, 3D-echocardiogram, body surface mapping, etc.-inconclusive, and are limited by technical challenges in implementation and interpretation, low acceptability by patients, and high cost (19). Other methods include measurement of electromechanical delay by tissue Doppler echocardiography (PA-TDI), which is an emerging parameter to measure left atrial fibrosis (20). Although there is a pressing need to better characterize 
LA abnormality or atrial cardiomyopathy to improve our ability to predict AF-related outcomes, currently available tools remain firmly in the realm of research, and are not ready to be used clinically at the bedside.

Alterations in atrial activation measured through analysis of P-wave morphology-P-wave indices (PWIs)-has been associated with atrial remodeling (21-23) and ischemic stroke (24-26). PWIs are also associated with increased risk of AF (27-29). In individuals with non-permanent AF, periods of sinus rhythm present an opportunity to detect underlying atrial cardiomyopathy through measurement of PWIs. These PWIs include P-wave axis, P-wave duration, advanced interatrial block (aIAB), and P-wave terminal force in lead V1 (PTFV1), and others. In this mini review, we define representative PWIs, discuss state-of-the-art knowledge on the relationship between abnormal PWIs and AF-related cardiovascular outcomes (focusing on ischemic stroke and SCD), and propose directions for future research. Our ultimate goal is to present a practical way forward to advance the emerging field of LA abnormality or atrial cardiomyopathy.

\section{P WAVE INDICES}

PWIs include $\mathrm{P}$-wave axis, $\mathrm{P}$-wave duration (maximum, minimum, and mean), aIAB, PTFV1, P-wave area (maximum, minimum, and mean), $\mathrm{P}$-wave dispersion, signal average $\mathrm{P}$-wave, and others. Of all PWIs, P-wave axis is the only one that is routinely reported on all standard 12-lead ECGs. Calculation of other PWIs requires ECG digitalization and specialized analytic software to allow for precise measurements making them impractical for everyday clinical use, particularly in the primary care setting. Therefore, compared with other PWIs, P-wave axis holds the distinct advantage of being readily available at the bedside for clinical use. In this review, we will focus on four PWIs that have been extensively reported in the literature: P-wave axis, P-wave duration, aIAB, and PTFV1.

\section{P-Wave Axis}

P-wave axis is a measure of the net direction of atrial depolarization. It is determined by measuring net positive or negative P-wave deflections on all six limb leads and calculating the net direction of electrical activity using the hexaxial reference system. Abnormal P-wave axis is defined as any value outside $0-75^{\circ}$ (Figure 1) (31).

\section{P-Wave Duration}

P-wave duration is a reflection of the time required for right and left atrial depolarization. It is measured from the conclusion of the T-P segment ( $\mathrm{P}$ wave onset) to return to baseline (PR interval). For biphasic P-waves, P-wave duration encompasses both positive and negative deflections from baseline. Prolonged P-wave duration is present if the maximum Pwave duration in any lead is $>120 \mathrm{~ms}$ on a standard 12-lead ECG (Figure 1) (32, 33).

\section{Advanced Inter-Atrial Block}

aIAB is an indicator of inter-atrial conduction block in the Bachman's bundle such that the LA is activated superiorly. It is defined as prolonged $\mathrm{P}$-wave duration + biphasic P-wave morphology in leads III and aVF with biphasic morphology or notched morphology in lead II (Figure 1) (32).

\section{P-Wave Terminal Force in Lead V1}

PTFV1 is a measure of LA activation. It is computed by multiplying the duration (ms) and the depth $(\mu \mathrm{V})$ of the downward deflection (terminal portion) of the P-wave in lead V1. Abnormal PTFV1 is defined as $\leq-4,000 \mu V^{*}$ ms (Figure 1) (33).

The difference between aIAB and prolonged P-wave duration seen in LA enlargement is worth noting. The key difference between advanced interatrial block (aIAB) and enlarged left atrium (LA) is the direction of the activation from right atrium (RA) to LA. In aIAB, the marked delay of activation from RA to LA across the blocked Bachmann Bundle forces the impulses in the RA to be directed toward the atrioventricular node first before progressing caudocephalically to depolarize the LA. This results in biphasic (typically positive-negative phases) and wide $\mathrm{P}$ waves in leads II, III, and aVF (34).

On the hand, in LA enlargement, LA depolarization is initiated in normal direction on arrival of the electrical wave at the atrial septum through Bachmann Bundle. However, depolarization takes a longer time within the LA due to enlargement. The delayed activation in LA due to larger size only leads to prolonged $\mathrm{P}$ wave duration without the positivenegative phases that are seen in aIAB. The notched $\mathrm{P}$ wave that is sometimes observed in enlarged LA occur as a result of the overlap between the depolarization of the RA and LA due to the longer time the LA takes in completing its activation (34).

\section{P WAVE INDICES AND ISCHEMIC STROKE}

In recent years, several epidemiological studies have implicated abnormal PWIs as independent risk factors for ischemic stroke (Table 1). Some of these studies indicate a stronger association with cardioembolic than thrombotic stroke (24) or with nonlacunar than lacunar stroke $(17,24)$, consistent with the notion that PWIs are a marker of abnormal atrial structure and function which promote thrombosis and subsequent embolism.

A recent study by Maheshwari et al. (30) went one step further to determine whether consideration of PWIs would improve ischemic stroke prediction in individuals with $\mathrm{AF}$, above and beyond the current paradigm, which is the $\mathrm{CHA}_{2} \mathrm{DS}_{2}-$ VASc (congestive heart failure, hypertension, age, diabetes, stroke, vascular disease, sex) score (36). Despite its many limitations $(37,38)$, the $\mathrm{CHA}_{2} \mathrm{DS}_{2}$-VASc is the most widely used scoring system to assess the risk of ischemic stroke and to determine the need for anticoagulation in people with AF. Using data from two prospective community-based cohort studiesAtherosclerosis Risk in Communities (ARIC) and Multi-Ethnic Study of Atherosclerosis (MESA)-Maheshwari et al. found that of the PWIs considered ( $\mathrm{P}$-wave axis, $\mathrm{P}$-wave duration, $\mathrm{aIAB}$, and PTFV1), abnormal P-wave axis was the only PWI associated 


\section{A Prolonged P-wave Duration}
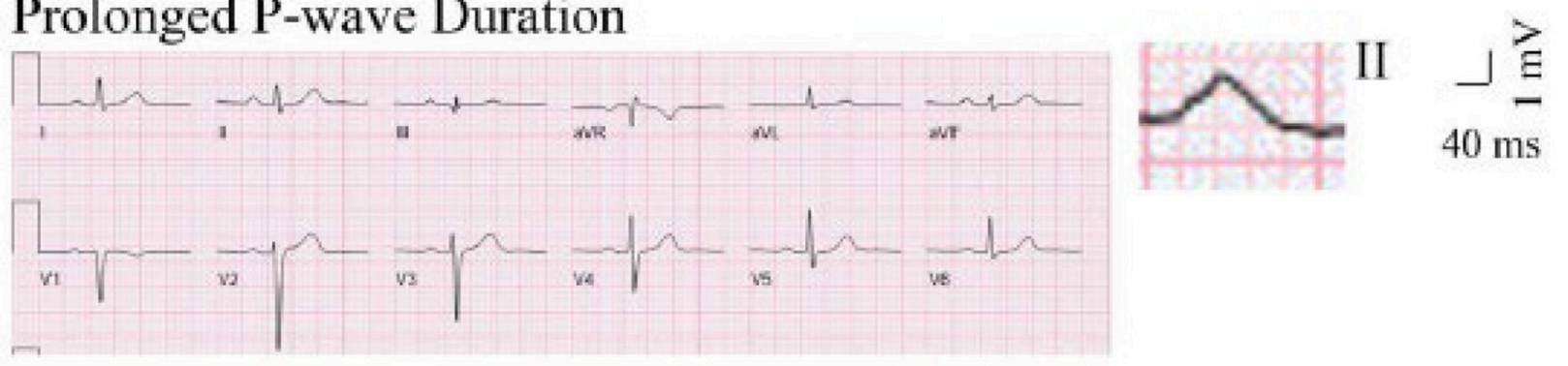

в Abnormal P-wave Axis
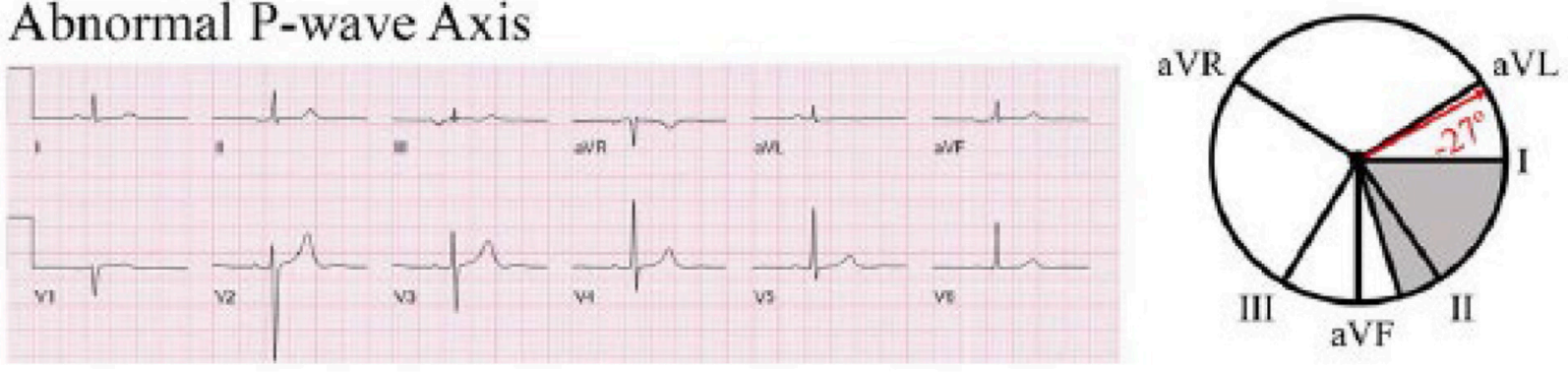

\section{c Abnormal P-wave Terminal Force in V1}
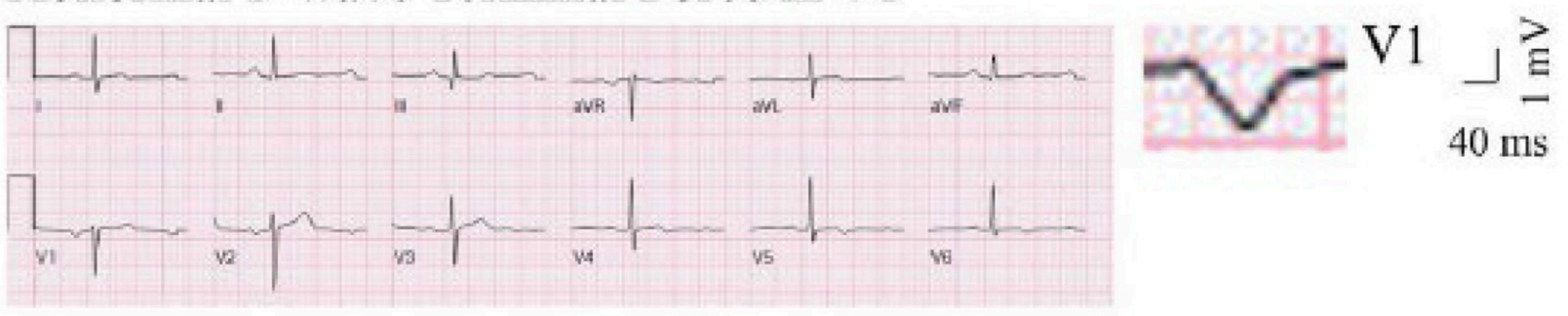

D Advanced Interatrial Block

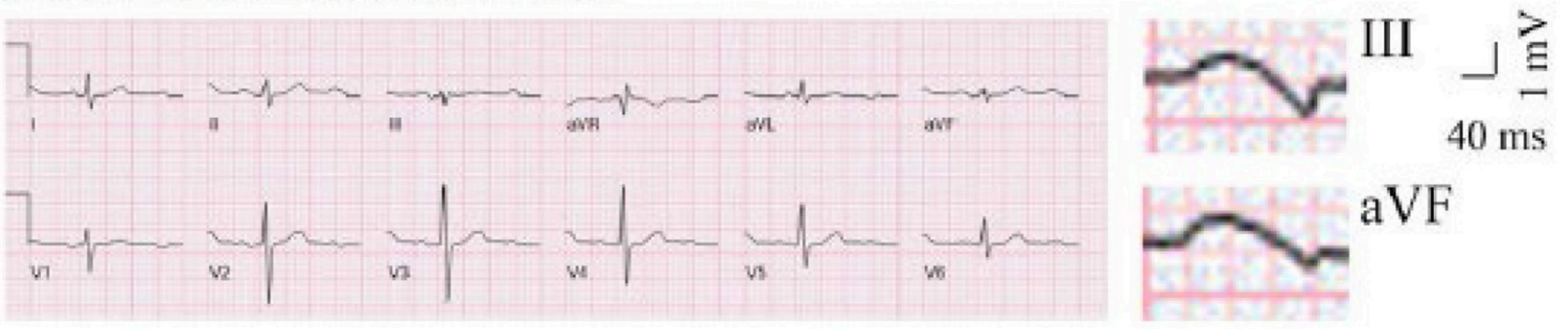

FIGURE 1 | Representative ECG tracings of abnormal P-wave indices. A through (D), Prolonged P-wave duration (A), abnormal P-wave axis (B), abnormal P-wave terminal force in V1 (C), and advanced interatrial block (D). (A) The maximal P-wave duration is seen in lead II (136 ms). (B) The gray area on the hexaxial reference system (lead $10^{\circ}$, lead $I 160^{\circ}$, aVF $90^{\circ}$, aVR $-150^{\circ}$, aVL $-30^{\circ}$ ) represents normal $\mathrm{P}$-wave axis $\left(0-75^{\circ}\right)$. The $\mathrm{P}$-wave axis on $\mathrm{B}$ is $-27^{\circ}$. (C) The $\mathrm{P}$-wave terminal force is $-9,632 \mu \mathrm{V}^{\star} \mathrm{ms}$ (amplitude $-112 \mu \mathrm{V}$, duration $86 \mathrm{~ms}$ ). (D) The maximal P-wave duration is seen in lead III (136 ms). Biphasic P-waves can be seen in III and aVF. This figure has been republished from Maheshwari et al. (30). Chen and Soliman are allowed to republish this figure, per American Heart Association Journal Policy.

with increased ischemic stroke risk independent of $\mathrm{CHA}_{2} \mathrm{DS}_{2}$ VASc variables, and that resulted in meaningful improvement in stroke prediction. The $\beta$ estimate of abnormal $\mathrm{P}$-wave axis in the regression model was approximately twice that of the $\mathrm{CHA}_{2} \mathrm{DS}_{2}$ VASc variables, and thus abnormal $\mathrm{P}$-wave axis was assigned 2 points to create the $\mathrm{P}_{2}-\mathrm{CHA}_{2} \mathrm{DS}_{2}$-VASc score. Compared with the $\mathrm{CHA}_{2} \mathrm{DS}_{2}$-VASc score, the $\mathrm{P}_{2}-\mathrm{CHA}_{2} \mathrm{DS}_{2}$-VASc score improved the C-statistic (95\% CI) from $0.60(0.51-0.69)$ to 0.67 $(0.60-0.75)$ in ARIC and $0.68(0.52-0.84)$ to $0.75(0.60-0.91)$ in MESA (validation cohort). In ARIC and MESA, the categorical net reclassification improvements $(95 \% \mathrm{CI})$ were $0.25(0.13-0.39)$ and $0.51(0.18-0.86)$, respectively, and the relative integrated discrimination improvement $(95 \% \mathrm{CI})$ were $1.19(0.96-1.44)$ and 0.82 (0.36-1.39), respectively. 
TABLE 1 | Selected studies relating abnormal P-wave indices with risk of ischemic stroke.

\begin{tabular}{|c|c|c|c|c|}
\hline References & P-wave indices & Outcome & Atrial fibrillation & Adjusted effect estimates \\
\hline Kamel et al. (16) & $\begin{array}{l}\text { PTFV1 } \\
\text { P-wave area } \\
\text { P-wave duration }\end{array}$ & Incident ischemic stroke & Excluded and adjusted & $\begin{array}{l}\text { PTFV1: HR per 1-SD increase, } 1.21 ; 95 \% \mathrm{Cl} \text {, } \\
\text { 1.02-1.44. } \\
\text { No associations with P-wave area and } \\
\text { P-wave duration. }\end{array}$ \\
\hline Kamel et al. (35) & $\begin{array}{l}\text { PTFV1 } \\
\text { P-wave area } \\
\text { P-wave duration }\end{array}$ & $\begin{array}{l}\text { Prevalent and incident } \\
\text { brain infarcts on MRI }\end{array}$ & Excluded and adjusted & $\begin{array}{l}\text { PTFV1: Associated with prevalent brain infarcts (RR } \\
\text { per SD, } 1.09 ; 95 \% \mathrm{Cl}, 1.04-1.16) \text { but not with } \\
\text { incident brain infarcts. } \\
\text { No associations with P-wave area and } \\
\text { P-wave duration. }\end{array}$ \\
\hline Kamel et al. (17) & PTFV1 & $\begin{array}{l}\text { Incident ischemic stroke } \\
\text { subtypes }\end{array}$ & Adjusted & $\begin{array}{l}\text { Associated with incident non-lacunar stroke (HR, } \\
\text { 1.49; 95\% Cl: 1.07-2.07) but not with lacunar } \\
\text { stroke. }\end{array}$ \\
\hline O’Neal et al. (25) & $\mathrm{al} A \mathrm{~B}$ & Incident ischemic stroke & Adjusted & HR, 1.63; 95\% Cl, 1.13-2.34. \\
\hline Maheshwari et al. (24) & P-wave axis & $\begin{array}{l}\text { Incident ischemic stroke } \\
\text { subtypes }\end{array}$ & Adjusted & $\begin{array}{l}\text { Ischemic stroke: HR, 1.50; 95\% Cl, 1.22-1.85. } \\
\text { Cardioembolic stroke: HR, 2.04; 95\% Cl, 1.42-2.95. } \\
\text { Thrombotic stroke: HR, 1.32; 95\% Cl, 1.03-1.71. }\end{array}$ \\
\hline Maheshwari et al. (30) & $\begin{array}{l}\text { PTFV1 } \\
\text { P-wave axis } \\
\text { P-wave duration } \\
\text { alAB }\end{array}$ & Incident ischemic stroke & Included & $\begin{array}{l}\text { P-wave axis: HR, 1.88; } 95 \% \mathrm{Cl}, 1.36-2.61 . \\
\text { alAB: } \mathrm{HR}, 2.93 ; 95 \% \mathrm{Cl}, 1.78-4.81 . \\
\text { No associations with PTFV1 and P-wave duration } \\
\text { Only P-wave axis resulted in significant improvement } \\
\text { in C-statistic and improvement in risk classification } \\
\text { of ischemic stroke compared with } \mathrm{CHA}_{2} \mathrm{DS}_{2} \text {-VASc. }\end{array}$ \\
\hline
\end{tabular}

Therefore, we now have some evidence to suggest that PWIs are not only associated with AF-related ischemic stroke, but they can also improve risk classification of ischemic stroke in people with AF. Before these PWIs-particularly abnormal Pwave axis_can be routinely used at the bedside, remaining knowledge gaps will need to be addressed as outlined in the final section of this review. In addition, some limitations of PWIs will need to be considered. For example, PWIs cannot be measured in patients with permanent AF.

\section{P WAVE INDICES AND SUDDEN CARDIAC DEATH}

AF is associated with a 2.5 -fold increased risk of SCD (8). Risk factors for SCD in people with AF include higher age, higher body mass index, coronary heart disease, hypertension, diabetes, cigarette smoking, left ventricular hypertrophy, higher heart rate, and lower albumin (39). Recent evidence also suggests that PWIs are independently associated with elevated risk of SCD.

Tereshchenko et al. (40) evaluated a simplified ECG metric of abnormal PTFV1-deep terminal negativity of $\mathrm{P}$ wave in V1 (DTNPV1) - in relation to SCD in ARIC. DTNPV1 was defined from the resting 12-lead ECG as presence of biphasic $\mathrm{P}$ wave (positive/negative) in $\mathrm{V} 1$ with the amplitude of the terminal negative phase $>100 \mu \mathrm{V}$. DTNPV1 was associated with an increased risk of SCD after multivariable adjustment including age, sex, coronary heart disease, AF, stroke, and heart failure (hazard ration [HR], 2.49; 95\% CI, 1.51-4.10). DTNPV1 also improved reclassification: additional $3.4 \%$ of individuals were appropriately reclassified into a higher SCD risk group, as compared with traditional coronary heart disease risk factors alone.
In another ARIC-based investigation, Maheshwari et al. evaluated the prospective association of prolonged P-wave duration with SCD (41). The multivariable HR (95\% CI) of prolonged P-wave duration for SCD was 1.70 (1.31-2.20). This association was attenuated but remained significant after updating covariates (including AF) to the end of follow-up with a HR of 1.35 (1.04-1.76).

Hence, evidence is accumulating to suggest that abnormal PWIs are associated with increased SCD incidence. The mechanisms remain unclear and may including the following: First, despite adjustment for cardiovascular risk factors or conditions, the abnormal PWI-SCD association may still be partially explained by the development of coronary heart disease, heart failure, or AF. Second, abnormal PWIs may reflect an arrhythmogenic myocardial substrate in the atrium and ventricle. In fact, the degree of interstitial left ventricular fibrosis on cardiac magnetic resonance imaging has been reported to be linearly associated with both increasing P-wave duration and increasing negative PTFV1 (42). Certainly, fibrotic remodeling can represent a common substrate between atrial and ventricular arrhythmias and may, in part, explain the relationships between markers of LA abnormality or atrial cardiomyopathy and SCD.

\section{FUTURE DIRECTIONS AND CONCLUSIONS}

We propose additional investigation in the following areas to advance our understanding of AF-related cardiovascular outcomes.

- Replication of currently know associations in other independent cohorts: This is particularly important with respect to the $\mathrm{P}_{2}-\mathrm{CHA}_{2} \mathrm{DS}_{2}$-VASc score. Before this 
novel score can enter the realm of clinical medicine, its performance will need to be validated in diverse cohorts, including cohorts of people with different racial or ethnic groups.

- Association with other AF-related outcomes: Thus far, data on the relationship of PWIs to cognitive decline, dementia, or heart failure are lacking. More research on these outcomes is needed to confirm the prognostic value of PWIs in people with AF.

- Biological correlation of abnormal PWIs: The PRIMERI study reported that after adjustment for demographic characteristics, body mass index, maximum LA volume index, presence of scar, and left ventricular (LV) mass index, each decile increase in LV interstitial fibrosis was associated with $0.76 \mathrm{mV}^{*} \mathrm{~ms}$ increase in negative abnormal PTFV1 (95\% $\mathrm{CI},-1.42$ to -0.09$)$ and $5.4 \mathrm{~ms}$ prolongation of $\mathrm{P}$-wave duration (95\% CI, 0.9-10.0) (42). Maheshwari et al. found that abnormal $\mathrm{P}$-wave axis and prolonged $\mathrm{P}$-wave duration were both associated with lower LA ejection fraction (30). In addition, abnormal P-wave axis was associated with lower LA global longitudinal strain. More research is needed to confirm the relationship of abnormal PWIs to alterations in LA and LV macro- and micro-structure, systolic and diastolic function, and global electrical activation.

- Role of anticoagulation for abnormal PWIs in the absence of AF: AtRial Cardiopathy and Antithrombotic Drugs In Prevention After Cryptogenic Stroke (ARCADIA) (NCT03192215) is an

\section{REFERENCES}

1. Go AS, Hylek EM, Phillips KA, Chang Y, Henault LE, Selby JV, et al. Prevalence of diagnosed atrial fibrillation in adults: national implications for rhythm management and stroke prevention: the AnTicoagulation and Risk Factors in Atrial Fibrillation (ATRIA) study. JAMA. (2001) 285:2370-5. doi: 10.1001/jama.285.18.2370

2. Miyasaka Y, Barnes ME, Gersh BJ, Cha SS, Bailey KR, Abhayaratna $\mathrm{WP}$, et al. Secular trends in incidence of atrial fibrillation in Olmsted County, Minnesota, 1980 to 2000, and implications on the projections for future prevalence. Circulation. (2006) 114:119-25. doi: 10.1161/CIRCULATIONAHA.105.595140

3. Wolf PA, Abbott RD, Kannel WB. Atrial fibrillation as an independent risk factor for stroke: the framingham study. Stroke. (1991) 22:983-8. doi: 10.1161/01.STR.22.8.983

4. Wang TJ, Larson MG, Levy D, Vasan RS, Leip EP, Wolf PA, et al. Temporal relations of atrial fibrillation and congestive heart failure and their joint influence on mortality: the Framingham Heart Study. Circulation. (2003) 107:2920-5. doi: 10.1161/01.CIR.0000072767.89944.6E

5. Chen LY, Lopez FL, Gottesman RF, Huxley RR, Agarwal SK, Loehr L, et al. Atrial fibrillation and cognitive decline-the role of subclinical cerebral infarcts the atherosclerosis risk in communities study. Stroke. (2014) 45:2568-74. doi: 10.1161/STROKEAHA.114.005243

6. Chen LY, Norby FL, Gottesman RF, Mosley TH, Soliman EZ, Agarwal SK, et al. Association of atrial fibrillation with cognitive decline and dementia over 20 years: the ARIC-NCS (Atherosclerosis Risk in Communities Neurocognitive Study). J Am Heart Assoc. (2018) 7:e007301. doi: 10.1161/JAHA.117.007301

7. Soliman EZ, Lopez F, O'Neal WT, Chen LY, Bengtson L, Zhang $\mathrm{ZM}$, et al. Atrial fibrillation and risk of ST-segment-elevation versus non-ST-segment-elevation myocardial infarction the atherosclerosis risk in communities (ARIC) study. Circulation. (2015) 131:1843-50. doi: 10.1161/CIRCULATIONAHA.114.014145
$\mathrm{NIH}$-funded randomized controlled trial (RCT) which tests the hypothesis that apixaban is superior to aspirin for the prevention of recurrent stroke in patients with cryptogenic ischemic stroke and atrial cardiomyopathy. The latter is defined by PTFV $1>5,000 \mu \mathrm{V}^{*} \mathrm{~ms}$, LA size index $\geq 3.0 \mathrm{~cm} / \mathrm{m}^{2}$ on echocardiogram, and serum amino terminal pro-B-type natriuretic peptide $>250 \mathrm{pg} / \mathrm{mL}$. RCTs focused on using oral anticoagulants for the primary prevention of ischemic stroke in people without AF but with abnormal PWIs will be the litmus test for the clinical utility of PWIs.

In conclusion, PWIs may emerge as a practical method to identify individuals at risk of adverse cardiovascular outcomes due to underlying LA abnormality or atrial cardiomyopathy. Before PWIs can change current clinical practice, more work will be needed to confirm their predictive value, elucidate their biological underpinnings, and ultimately, define the risks, and benefits of anticoagulation for abnormal PWIs to prevent ischemic stroke.

\section{AUTHOR CONTRIBUTIONS}

LC is the primary author and ES is the contributing author.

\section{FUNDING}

LC is supported by R01 HL126637 and R01HL141288.
8. Chen LY, Sotoodehnia N, BuŽková P, Lopez FL, Yee LM, Heckbert SR, et al. Atrial fibrillation and the risk of sudden cardiac death: the atherosclerosis risk in communities (ARIC) study and cardiovascular health study (CHS). JAMA Intern Med. (2013) 173:29-35. doi: 10.1001/2013.jamainternmed.744

9. Eisen A, Ruff CT, Braunwald E, Nordio F, Corbalan R, Dalby A, et al. Sudden cardiac death in patients with atrial fibrillation: insights from the ENGAGE AF-TIMI 48 Trial. J Am Heart Assoc. (2016) 5:e003735. doi: 10.1161/JAHA.116.003735

10. Okin PM, Bang CN, Wachtell K, Hille DA, Kjeldsen SE, Dahlof $\mathrm{B}$, et al. Relationship of sudden cardiac death to new-onset atrial fibrillation in hypertensive patients with left ventricular hypertrophy. Circul Arrhyth Electrophysiol. (2013) 6:243-51. doi: 10.1161/CIRCEP.112.9 77777

11. Benjamin EJ, Wolf PA, D’Agostino RB, Silbershatz H, Kannel WB, Levy D. Impact of atrial fibrillation on the risk of death: the framingham heart study. Circulation. (1998) 98:946-52. doi: 10.1161/01.CIR.98.10.946

12. Conen D, Chae CU, Glynn RJ, Tedrow UB, Everett BM, Buring JE, et al. Risk of death and cardiovascular events in initially healthy women with new-onset atrial fibrillation. JAMA. (2011) 305:2080-7. doi: 10.1001/jama. 2011.659

13. Watson T, Shantsila E, Lip GYH. Mechanisms of thrombogenesis in atrial fibrillation: virchow's triad revisited. Lancet. (2009) 373:155-66. doi: 10.1016/S0140-6736(09)60040-4

14. Brambatti M, Connolly SJ, Gold MR, Morillo CA, Capucci A, Muto C, et al. Temporal relationship between subclinical atrial fibrillation and embolic events. Circulation. (2014) 129:2094-99. doi: 10.1161/CIRCULATIONAHA.113.007825

15. Martin DT, Bersohn MM, Waldo AL, Wathen MS, Choucair WK, Lip GYH, et al. Randomized trial of atrial arrhythmia monitoring to guide anticoagulation in patients with implanted defibrillator and cardiac resynchronization devices. Eur Heart J. (2015) 36:1660-68. doi: 10.1093/eurheartj/ehv115 
16. Kamel H, Soliman EZ, Heckbert SR, Kronmal RA, Longstreth WT, Nazarian $\mathrm{S}$, et al. P-wave morphology and the risk of incident ischemic stroke in the multi-ethnic study of atherosclerosis. Stroke. (2014) 45:2786-88. doi: 10.1161/STROKEAHA.114.006364

17. Kamel H, O'Neal WT, Okin PM, Loehr LR, Alonso A, Soliman EZ. Electrocardiographic left atrial abnormality and stroke subtype in the atherosclerosis risk in communities study. Ann Neurol. (2015) 78:670-8. doi: 10.1002/ana.24482

18. Goette A, Kalman JM, Aguinaga L, Akar J, Cabrera JA, Chen SA, et al. EHRA/HRS/APHRS/SOLAECE expert consensus on atrial cardiomyopathies: definition, characterization, and clinical implication. Heart Rhythm. (2017) 14:e3-40. doi: 10.1016/j.hrthm.2016.05.028

19. Goldberger JJ, Arora R, Green D, Greenland P, Lee DC, Lloyd-Jones DM, et al. Evaluating the atrial myopathy underlying atrial fibrillation identifying the arrhythmogenic and thrombogenic substrate. Circulation. (2015) 132:278-91. doi: 10.1161/CIRCULATIONAHA.115.016795

20. Leung $M$, Biostat $M$, Abou R, van Rosendael PJ, van der Bijl P, van Wijngaarden SE, et al. Relation of echocardiographic markers of left atrial fibrosis to atrial fibrillation burden. Am J Cardiol. (2018) 122:584-91. doi: 10.1016/j.amjcard.2018.04.047

21. Goyal SB, Spodick DH. Electromechanical dysfunction of the left atrium associated with interatrial block. Am Heart J. (2001) 142:823-7. doi: $10.1067 / \mathrm{mhj} .2001 .118110$

22. Ariyarajah V, Mercado K, Apiyasawat S, Puri P, Spodick DH. Correlation of left atrial size with p-wave duration in interatrial block. Chest. (2005) 128:2615-8. doi: 10.1378/chest.128.4.2615

23. Jin L, Weisse AB, Hernandez F, Jordan T. Significance of electrocardiographic isolated abnormal terminal P-wave force (left atrial abnormality). An echocardiographic and clinical correlation. Arch Intern Med. (1988) 148:1545-9. doi: 10.1001/archinte.148.7.1545

24. Maheshwari A, Norby FL, Soliman EZ, Koene RJ, Rooney MR, O’Neal WT, et al. Abnormal P-wave axis and ischemic stroke: the ARIC study (Atherosclerosis Risk In Communities). Stroke. (2017) 48:2060-5. doi: 10.1161/STROKEAHA.117.017226

25. O’Neal WT, Kamel H, Zhang ZM, Chen LY, Alonso A, Soliman EZ. Advanced interatrial block and ischemic stroke: the atherosclerosis risk in communities study. Neurology. (2016) 87:352-6. doi: 10.1212/WNL.0000000000002888

26. Soliman EZ, Prineas RJ, Case LD, Zhang ZM, Goff DC. Ethnic distribution of ECG predictors of atrial fibrillation and its impact on understanding the ethnic distribution of ischemic stroke in the atherosclerosis risk in communities (ARIC) study. Stroke. (2009) 40:1204-11. doi: 10.1161/STROKEAHA.108.534735

27. Maheshwari A, Norby FL, Soliman EZ, Koene R, Rooney M, O’Neal WT, et al. Refining prediction of atrial fibrillation risk in the general population with analysis of $\mathrm{P}$-wave axis (from the atherosclerosis risk in communities study). Am J Cardiol. (2017) 120:1980-4. doi: 10.1016/j.amjcard.2017.08.015

28. O’Neal WT, Zhang ZM, Loehr LR, Chen LY, Alonso A, Soliman EZ. Electrocardiographic advanced interatrial block and atrial fibrillation risk in the general population. Am J Cardiol. (2016) 117:1755-9. doi: 10.1016/j.amjcard.2016.03.013

29. Magnani JW, Johnson VM, Sullivan LM, Gorodeski EZ, Schnabel RB, Lubitz SA, et al. $\mathrm{P}$ Wave duration and risk of longitudinal atrial fibrillation in persons $>=60$ years old (from the framingham heart study). Am J Cardiol. (2011) 107:917-21. doi: 10.1016/j.amjcard.2010.10.075

30. Maheshwari A, Norby FL, Roetker NS, Soliman EZ, Koene RJ, Rooney $\mathrm{MR}$, et al. Refining prediction of atrial fibrillation-related stroke using the P2-CHA2DS2-VASc score. Circulation. (2019) 139:180-91. doi: 10.1161/CIRCULATIONAHA.118.035411

31. Wagner G. Marriott's Practical Electrocardiography. 11th ed. Philadelphia, PA: Lippincott Williams and Wilkins. (2007).
32. de Luna AB, Platonov P, Cosio FG, Cygankiewicz I, Pastore C, Baranowski R, et al. Interatrial blocks. A separate entity from left atrial enlargement: a consensus report. J Electrocardiol. (2012) 45:445-51. doi: 10.1016/j.jelectrocard.2012.06.029

33. Soliman EZ, Alonso A, Misialek JR, Jain A, Watson KE, Lloyd-Jones DM, et al. Reference ranges of PR duration and P-wave indices in individuals free of cardiovascular disease: the multi-ethnic study of atherosclerosis (MESA). J Electrocardiol. (2013) 46:702-6. doi: 10.1016/j.jelectrocard.2013. 05.006

34. Baranchuk A, Alexander B, Cinier G, Martinez-Selles M, Tekkesin AI, Elousa $\mathrm{R}$, et al. Bayes' syndrome: time to consider early anticoagulation? North Clin Istanb. (2018) 5:370-8. doi: 10.14744\%2Fnci.2017.60251

35. Kamel H, Bartz TM, Longstreth WT, Okin PM, Thacker EL, Patton KK, et al. Association between left atrial abnormality on ECG and vascular brain injury on MRI in the cardiovascular health study. Stroke. (2015) 46:711-6. doi: 10.1161/STROKEAHA.114.007762

36. Lip GYH, Nieuwlaat R, Pisters R, Lane DA, Crijns HJGM. Refining clinical risk stratification for predicting stroke and thromboembolism in atrial fibrillation using a novel risk factor-based approach the euro heart survey on atrial fibrillation. Chest. (2010) 137:263-72. doi: 10.1378/chest. 09-1584

37. Chen LY, Norby FL, Chamberlain AM, MacLehose RF, Bengtson LG, Lutsey PL, et al. CHA2DS2-VASc score and stroke prediction in atrial fibrillation in whites, blacks, and hispanics. Stroke. (2018). doi: 10.1161/STROKEAHA.118.021453. [Epub ahead of print].

38. Chen JY, Zhang AD, Lu HY, Guo J, Wang FF, Li ZC. CHADS2 versus CHA2DS2-VASc score in assessing the stroke and thromboembolism risk stratification in patients with atrial fibrillation: a systematic review and meta-analysis. J Geriatr Cardiol. (2013) 10:258-66. doi: 10.3969/j.issn.1671-5411.2013.03.004

39. Koene RJ, Norby FL, Maheshwari A, Rooney MR, Soliman EZ, Alonso A, et al. Predictors of sudden cardiac death in atrial fibrillation: the atherosclerosis risk in communities (ARIC) study. PLoS ONE. (2017) 12:e0187659. doi: 10.1371/journal.pone.0187659

40. Tereshchenko LG, Henrikson CA, Sotoodehnia N, Arking DE, Agarwal SK, Siscovick DS, et al. Electrocardiographic deep terminal negativity of the $\mathrm{P}$ wave in $\mathrm{V}(1)$ and risk of sudden cardiac death: the Atherosclerosis Risk in Communities (ARIC) study. J Am Heart Assoc. (2014) 3:e001387. doi: 10.1161/JAHA.114.001387

41. Maheshwari A, Norby FL, Soliman EZ, Alraies MC, Adabag S, O'Neal WT, et al. Relation of prolonged P-wave duration to risk of sudden cardiac death in the general population (from the atherosclerosis risk in communities study). Am J Cardiol. (2017) 119:1302-6. doi: 10.1016/j.amjcard.2017. 01.012

42. Tiffany Win T, Ambale Venkatesh B, Volpe GJ, Mewton N, Rizzi P, Sharma RK, et al. Associations of electrocardiographic P-wave characteristics with left atrial function, and diffuse left ventricular fibrosis defined by cardiac magnetic resonance: the PRIMERI study. Heart Rhythm. (2015) 12:155-62. doi: 10.1016/j.hrthm.2014.09.044

Conflict of Interest Statement: The authors declare that the research was conducted in the absence of any commercial or financial relationships that could be construed as a potential conflict of interest.

Copyright (c) 2019 Chen and Soliman. This is an open-access article distributed under the terms of the Creative Commons Attribution License (CC BY). The use, distribution or reproduction in other forums is permitted, provided the original author(s) and the copyright owner(s) are credited and that the original publication in this journal is cited, in accordance with accepted academic practice. No use, distribution or reproduction is permitted which does not comply with these terms. 